\title{
GAMES BARGAINING: A PROPOSED APPLICATION OF THE THEORY OF GAMES TO COLLECTIVE BARGAINING
}

CoLLeCTIVE bargaining may perhaps be called an art; it has not yet become a science. But the approach of the sciences has brought to other fields dispassion; their methods have brought accuracy; their insights, illumination. And some of these benefits may be promised for collective bargaining by a new star in the firmament of the social sciences, the Theory of Games. A remarkable tool for the analysis of social behavior, the Theory of Games was conceived by John von Neumann and Oskar Morgenstern; ${ }^{1}$ and it has been adapted by John Nash to bargaining situations. ${ }^{2}$ Upon the foundation that Nash has provided, it may be that a new framework for collective bargaining can be erected. This comment is intended to suggest one such possible framework, a system that will be designated "Games Bargaining."

The essence of Games Bargaining is the derivation by a mathematical method of the "optimum solution" to a bargaining problem. This essential method is Nash's contribution. To state it generally, Nash characterizes a two-person bargaining situation, of which negotiation between employer and labor union is an example, as one in which two parties have the opportunity to collaborate for mutual benefit in more than one way. ${ }^{3}$ Hypothesizing two persons each of whom possesses items worth a certain number of "units of satisfaction" to himself and another number of units of satisfaction to the other, Nash offers a technique for determining which of the several possible trades between the parties will bring to them both simultaneously the greatest possible satisfaction. Identification of this trade-the "optimum solution" of a bargaining situation-reveals the potentialities of a bargain for each of the parties. It reveals, that is, the amount of satisfaction each can gain from a bargain, and the amount that each should reasonably expect to gain. The Nash technique, appropriately adapted, should offer to management and labor at the bargaining table a swift, impartial and accurate way of composing their conflicting demands.

1. Von Neumann \& Morgenstern, Theory of Games and Economic Brhanion (3d ed. 1953).

The Theory of Games has been hailed as "one of the major scientific achicuements of the first half of the Twentieth Century." Copeland, Book Review, 51 BulL. Ax. M.iTH. Soc'y 498 (1945).

Journalist John McDonald reports that von Neumann and Mrorgenstern have "set forth what is regarded in some circles of high intellect as possibly one of the most radical departures in modern thought since their colleague Einstein wrute the elementary formula for the conversion of matter into energy." McDonald, Poker: An American Game, Fortune, Mar. 1948, p. 128 .

2. Nash, The Bargaining Problem, is Econonietrucs 155 (1950). Those with a flair for mathematics can find in Nash's article a mathematical treatment of the application of the Theory of Games to bargaining situations similar to the ones dealt with in this article.

3. Ibid. 
It should offer as well a way of gaining for both the most that can be achieved from their bargaining situation.

For the purpose of maximizing the satisfaction of both labor and management in their bargain, the Games Bargaining to be outlined here not only adapts Nash's technique, but adds a new element to it. This new element, derived from the Lasswell-McDougal .concept of the "integrative solution," 4 is a broadening of the scope of the bargaining. By means of such broadening, the parties can enhance the satisfaction they will receive from the optimum solution derived by the Nash technique.

How Games Bargaining would achieve this broadening, and why, will be explained when the framework of the system has been sketched in. First, however, the foundation must be laid : the Nash technique must be explained, demonstrated and elaborated. For this purpose, a series of hypothetical bargaining situations of increasing complexity will be considered. In the first and simplest situation, the optimum solution will be obvious, and there will be no need for the Nash technique. The Nash technique will, however, be applied, and it will be shown that the optimum solution so derived corresponds with the intuitively obvious one. Then in examples of increasing complexity it will be shown that the Nash technique continues to provide a method of solving bargaining problems even where intuition is no longer a reliable guide. Finally, with the superstructure of Games Bargaining added to it, the technique will be applied to a hypothetical collective bargaining situation. ${ }^{5}$

\section{The Simplest Bargaining Situation}

Assume two intelligent boys, Bill and Jack, each of whom owns a toy, each of whom is free to trade if he wishes, and each of whom seeks to maximize the satisfaction he gets from his holdings. Bill owns a drum. He has played with

4. Lasswell \& McDougal, Mimeographed Work Papers for use in Fall, 1954 Law, Science and Policy Seminar at Yale Law School, pt. III, p. 167. See text at note 29 infra.

5. A justification for thus following in the methodological footsteps of the highly successful natural sciences-dealing first with the most simple and proceeding to a consideration of the complex-is offered by von Neumann and Morgenstern:

"[T] $T$ reatment of these manageable problems may lead to results which are already fairly well known, but the exact proofs may nevertheless be lacking. . . . The movements of the planets were known long before their courses had been calculated and explained by Newton's theory, and the same applies in many smaller and less dramatic instances. ... [C]ertain results . . . may be known already. Yet it is of interest to derive them again from an exact theory.

". ...

"The great progress in every science came when, in the study of problems which were modest as compared 'with ultinate aims; methods were developed which could be extended further and further. The free fall is a very trivial physical phenomenon, but it was the study of this exceedingly simple fact and its comparison with the astronomical material, which brought forth [Newton's] mechanics.

". . . The sound procedure is to obtain first utmost precision and mastery in a limited field, and then to proceed to another, somewhat wider one, and so on."

Vin NeUmanN \& MoRgenstern, op. cit. supra note 1, at 6-7. 
this drum for the past year, and now finds that it is not as much fun to bang the drum as it was when he first got it. Bill now regards this drum as worth only I unit of satisfaction. Jack, however, has no drum. He has always wanted one and, wanting it badly, considers a drum worth 5 units of satisfaction. Jack himself owns a truck. He has owned this truck for a year, and since he has tired of playing with it he regards it as worth only 1 unit of satisfaction. Bill, on the other hand, has no truck, and would like to have one. In fact, he would consider Jack's truck worth 5 units of satisfaction.

\section{The Intuitively Obvious Optimum Solution}

It is immediately obvious that this is a situation ripe for a trade. Bill should trade his drum to Jack for the truck. In doing so Bill will be giving up a drum he regards as worth 1 in exchange for a truck he regards as worth 5 , gaining 4 units of satisfaction on the trade. Similarly, Jack will give up a truck he regards as worth 1 in exchange for a drum he regards as worth 5 , so he too can gain 4 units of satisfaction from a trade.

\section{Obtaining the Optimum Solution by Means of Theory of Games Matrices}

In this simple bargaining situation there are a number of solutions, not just the optimum solution obtained by intuition. Each party has two alternative courses of action, or strategies. Bill can:

Jack can:

B-1 give up the drum

B-2 not give up the drum

$\mathrm{J}-1$ give up the truck

$\mathrm{J}-2$ not give up the truck

The existence of two alternative strategies for each party means that there are four possible solutions to this simple bargaining problem. They are:

$$
\begin{aligned}
& (\mathrm{B}-1, \mathrm{~J}-1) \\
& (\mathrm{B}-1, \mathrm{~J}-2) \\
& (\mathrm{B}-2, \mathrm{~J}-1) \\
& (\mathrm{B}-2, \mathrm{~J}-2)
\end{aligned}
$$

Each solution will produce a different "pay-off" of satisfaction for each of the parties. These pay-offs can be presented in the form of matrices that show how each of the four solutions looks from the viewpoint of each of the parties. If Bill gives up the drum and Jack gives up the truck, $(B-1, J-1)$, Bill will gain 4 (Table 1).

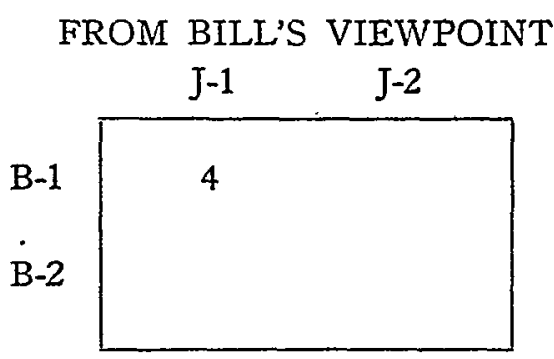

Table 1 
If Bill gives up the drum and Jack does not give up the truck, (B-1, J-2), Bill will lose 1 (Table 2).

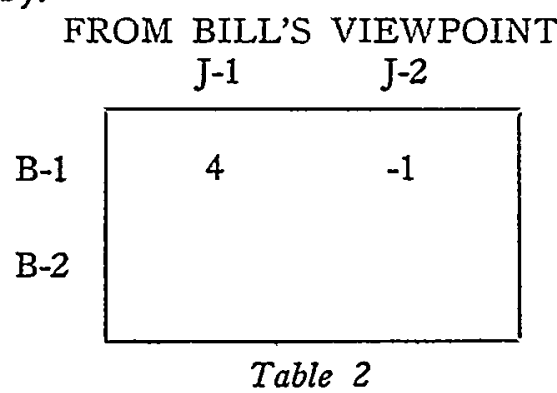

If Bill does not give up the drum but Jack gives up the truck, (B-2, J-1), Bill will gain 5 (Table 3).

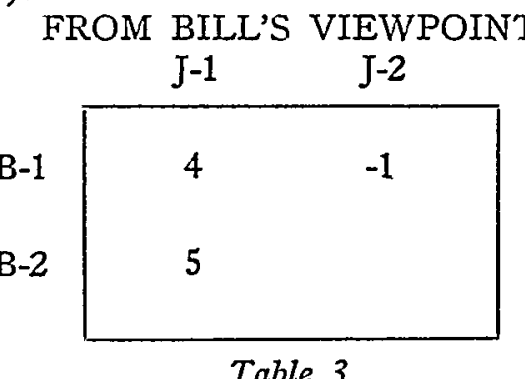

And finally, if Bill does not give up the drum, and Jack does not give up the truck, (B-2, J-2), Bill will gain 0 (Table 4).

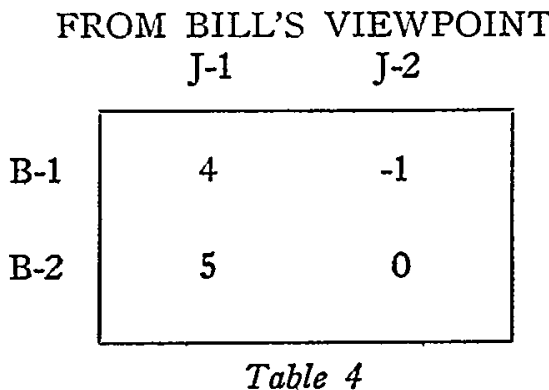

Similarly, a pay-off matrix can he constructed from Jack's viewpoint (Table 5).

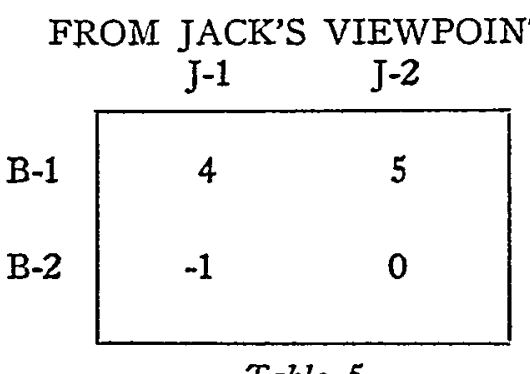

Table 5 
Finally, the viewpoints: of the two parties can be combined in a single matrix which will show the value of each of the solutions to the parties jointly. This "product of pay-offs" matrix is obtained from the following computational table (Table 6).

\begin{tabular}{|c|c|c|c|c|c|}
\hline SOLUTIONS & $\begin{array}{l}\text { FROM BILL'S } \\
\text { VIEWPOINT }\end{array}$ & & $\begin{array}{l}\text { FROM JACK'S } \\
\text { VIEWPOINT }\end{array}$ & & $\begin{array}{l}\text { PRODUCT OF } \\
\text { PAY-OFFS }\end{array}$ \\
\hline $\begin{array}{l}(\mathrm{B}-1, \mathrm{~J}-1) \\
(\mathrm{B}-1, \mathrm{~J}-2) \\
(\mathrm{B}-2, \mathrm{~J}-1) \\
(\mathrm{B}-2, \mathrm{~J}-2)\end{array}$ & $\begin{array}{r}4 \\
-1 \\
5 \\
-\quad 0\end{array}$ & $\begin{array}{l}x \\
x \\
x \\
x\end{array}$ & $\begin{array}{r}4 \\
5 \\
-1 \\
0\end{array}$ & $\begin{array}{l}= \\
\equiv \\
\equiv \\
=\end{array}$ & $\begin{array}{l}16 \\
-5 \\
-5 \\
0\end{array}$ \\
\hline
\end{tabular}

Table 6

And the following matrix results (Table 7). PRODÜCT OF PAY-OFFS

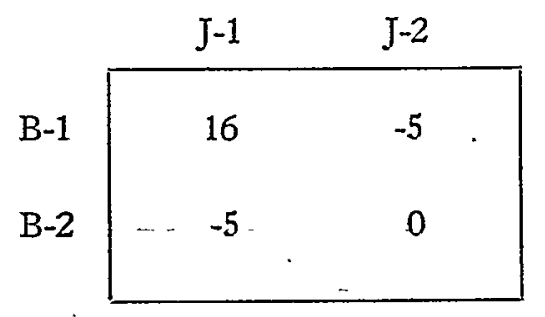

Table 7

There are two things about the product of pay-offs matrix that should be noticed: first, that $(B-1, J-1)$ is the solution that was found intuitively to be the optimum solution; second, that the pay-off for $(\mathrm{B}-1, \mathrm{~J}-1)$ in the product of pay-offs matrix, 16, is the maximum pay-off in this matrix. Hence, it is seen that for the simplest bargaining problem the optimum solution is that solution for which the pay-off in the product of pay-offs matrix is a maximum. What Nash has indicated is that the optimum solution for any such bargaining problem, no matter how complex, is that solution (or solutions) for which the product of pay-offs is gieatest. That this is true will be shown in examples of increasing complexity.

: It may be recalled that the optimum solution for the parties in a given bargaining situation was said to define the amount of satisfaction each party should reasonably expect to get from the situation. ${ }^{6}$. From Bill's provincial viewpoint the "best" solution would be (B-2, J-1), from which he would gain 5. But Bill should not reasonably expect Jack to go along with $(\mathrm{B}-2, \mathrm{~J}-1)$ because in this solution Jack suffers a loss of $\dot{1}$. Similarly, 'from Jack's provincial viewpoint the best solution would be (B-1, J-2), from which he would gain 5 ; but Jack should not reasonably expect Bill to go along with $(\mathrm{B}-1, \mathrm{~J}-2)$ because in this

6. See text following note 3 supra. 
solution Bill suffers a loss of 1 . The best solution from one party's viewpoint will always be the one in which the other party gives up everything he owns and obtains nothing in return. Since the other party can hardly be expected to accept so lopsided a trade, the optimum solution is one that is somewhere between the two parties' provincially best solutions. The optimum solution will generally be one in which both parties have gained from the bargain; it will indicate the most that each party can get, and the most that each should reasonably expect to get from the situation.

\section{Graphic Representation of Possible Solutions}

In his general proof of the derivation of the optimum solution Nash uses a graphic representation, rather than the matrix forms just described. ${ }^{7}$ By his method of plotting the products of pay-offs on a system of Cartesian coordinates representing the two parties' viewpoints, the simplest bargaining situation can be shown as in Figure 1.

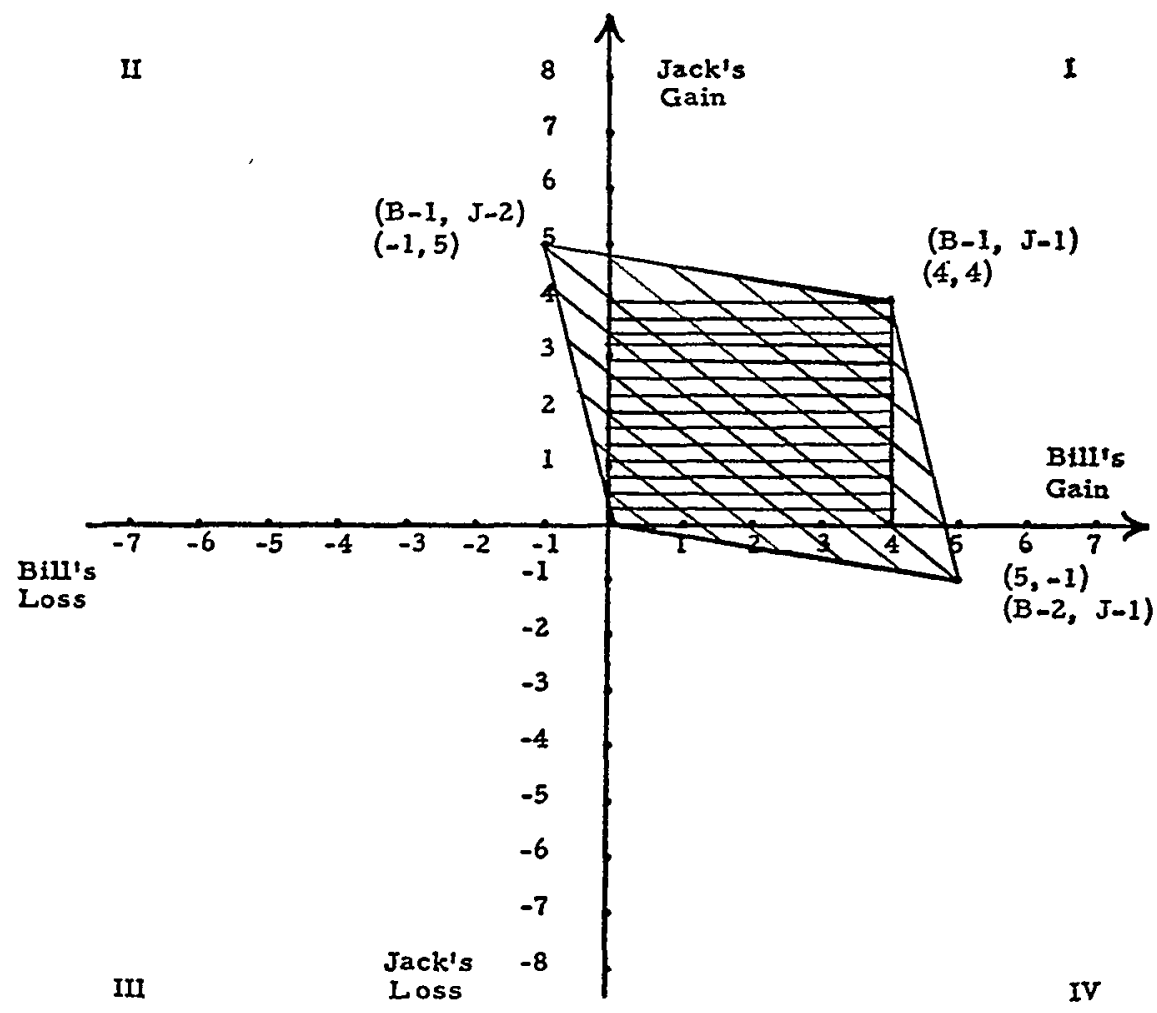

Figure 1

7. The author alone should be saddled with responsibility for any errors in connection with either the matrix method or the systematic trial-and-error method introduced below. Nash did not employ either method in his technique for obtaining optimum solutions; he should not be blamed for any mistakes in the treatment of them here. 
When all the possible solutions to a bargaining situation are plotted on a graph, there can be constructed a polygon that encloses all the points plotted (in Figmo 1, the diagonally shaded parallelogram). The point that represents the optimum solution-the maximum product of pay-offs-will occur on this polygon, in the first quadrant. It will be the point from which perpendiculars to the $\mathrm{X}$ and $\mathrm{Y}$ axes form the largest rectangle. ${ }^{8}$ In Figure 1, the optimum solution is indicated by the point $(4,4)$, since perpendiculars from this point to the axes form the largest rectangle (horizontally shaded square) within the polygon in the first quadrant. This point represents the solution ( $\mathrm{B}-1, \mathrm{~J}-1$ ), which, as has been seen, was also found to be the optimum solution derived by the intuitive method and the matrix method.

So far three methods of obtaining the optimum solution to a bargaining situation have been examined: the intuitive method, the matrix method and the graphic method. By each of the methods the same optimum solution, (B-1, $\mathrm{J}-1$ ), was arrived at. As hypotheticals of increasing complexity are considered, it will be seen that the intuitive method loses its usefulness. The matrix and graphic methods will continue to point to the optimum solution, but they will become increasingly unwieldly. And so in the next hypothetical a fourth methorl will be introduced, which will be workable even in situations as complex as those typically found in real labor-management collective bargaining.

\section{A Bargaining Situation Slightly More Complex}

For a hypothetical bargaining situation that is slightly more complex, assume the same two intelligent individuals, Bill and Jack, who have the same freedom to trade or not and the same objective of maximizing their position as they did in the previous example; but assume that each has three items that he might trade. These items, and their valuations, are as follows:

\begin{tabular}{llcc} 
& Bill's Items & Bill's Valuation & Tack's Valuation \\
\cline { 2 - 3 } B-1 & Train & 1 & 3 \\
B-2 & Car & 2 & 2 \\
B-3 & Tractor & 3 & 1 \\
& Jack's Items & & \\
J-1 & Ruler & 1 & 3 \\
J-2 & Pencil & 2 & 2 \\
J-3 & Pen & 3 & 1
\end{tabular}

\section{The Intuitive Method}

Here, once again, is a bargaining situation that is readily recognized as ripe for a trade. It is immediately obvious that Bill's train should be traded for

8. The rectangle that is largest in area, given a fixed sum of the parties' gains, would be a square. Thus, if the optimum solution to a bargaining situation resulted in gains of $S$ and 6 , the rectangle would be $S \times 6$, enclosing a product of pay-offs of 48 . But for the same total gain in the situation, $14(8+6)$, an even better solution would give gains of 7 and $7(7+7=14)$. This solution would give a product of pay-offs of 49 , and appear on the graph as a square. 
Jack's pen. If this trade is consummated each party will gain 2 units of satisfaction. Furthermore, it is obvious that a gain of 2 is the most that each party should reasonably expect to get from this bargaining situation. The intuitive conclusion is that train in exchange for pen is the optimum solution to this problem.

It will be seen as well that the same result can be achieved by a trade of Bill's train and car for Jack's pen and pencil. Here also, each party gains 2 from the transaction. This poses the question whether there may be more than one optimum solution; and the answer to the question is yes. In fact, one of the insights offered by the Theory of Games is that in many social situations there are multiple optimum solutions. ${ }^{9}$

The important thing to observe about the optimum solutions in this example is that they will also be obtained by each of the other methods. It should also be noted that in bargaining at this level of complexity, the intuitive method is still perfectly adequate, but the matrix method and the graphic method are already becoming cumbersome.'

\section{The Matrix Method}

Each of the parties in this situation has eight alternative strategies $\mathbf{1 0}^{\mathbf{1 0}}$

\section{Bill's Alternative Strategies}

$\begin{array}{ll}\text { B-1.2.3 } & \text { give up train, car and tractor } \\ \text { B-1.2 } & \text { give up train and car } \\ \text { B-1.3 } & \text { give up train and tractor } \\ \text { B-2.3 } & \text { give up car and tractor } \\ \text { B-1 } & \text { give up train } \\ \text { B-2 } & \text { give up car } \\ \text { B-3 } & \text { give up tractor } \\ \text { B-0 } & \text { give up nothing } \\ & \quad \text { Jack's Alternative Strategies } \\ \text { J-1.2.3 } & \text { give up ruler, pencil and pen } \\ \text { J-1.2 } & \text { give up ruler and pencil } \\ \text { J-1.3 } & \text { give up ruler and pen } \\ \text { J-2.3 } & \text { give up pencil and pen } \\ \text { J-1 } & \text { give up ruler } \\ \text { J-2 } & \text { give up pencil } \\ J-3 & \text { give up pen } \\ \text { J-0 } & \text { give up nothing }\end{array}$

9. "[M]uch of our thinking about politics, economics and social life is based on the tacit assumption that there is one 'best' solution for any set of given conditions and desires. This leads often to heated argument about the presumed all around 'superiority' of this or that political or economic system, or the counter assertion that almost any system of solutions should be workable. The authors of game theory deal explicitly with this problem of multiple solutions, and they go well beyond the classic emphasis of Montesquieu in suggesting that, in general, solutions are not unique. Indeed, in most cases, they suggest, a multiplicity of solutions are to be observed." Deutsch, Game Theory and Politics: Sane Problens of Application, 20 Can. J. Econ. \& PoL. Scr. 77-83 (1954).

10. $B-1.2$ represents giving up $B-1$ and $B-2 ; B-1.3$ represents giving up $B-1$ and $B-3$; $\mathrm{B}-1.2 .3$, giving up $\mathrm{B}-1, \mathrm{~B}-2$ and $\mathrm{B}-3$; etc. 
Once again the pay-off matrices of the possible bargains from each party's viewpoint can be constructed (Tables $8 \& 9$ ), and the product of payoffs matrix obtained from them (Table 10).

\begin{tabular}{|l|c|c|c|c|c|c|c|c|}
\hline \multicolumn{1}{|c|}{ FROM BILL'S VIEWPOINT } \\
\hline & $\mathrm{J}-1.2 .3$ & $\mathrm{~J}-1.2$ & $\mathrm{~J}-1.3$ & $\mathrm{~J}-2.3$ & $\mathrm{~J}-1$ & $\mathrm{~J}-2$ & $\mathrm{~J}-3$ & $\mathrm{~J}-0$ \\
\hline B-1.2.3 & 0 & -3 & -2 & -1 & -5 & -4 & -3 & -6 \\
B-1.2 & 3 & 0 & 1 & 2 & -2 & -1 & 0 & -3 \\
B-1.3 & 2 & -1 & 0 & 1 & -3 & -2 & -1 & -4 \\
B-2.3 & 1 & -2 & -1 & 0 & -4 & -3 & -2 & -5 \\
B-1 & 5 & 2 & 3 & 4 & 0 & 1 & 2 & -1 \\
B-2 & 4 & 1 & 2 & 3 & -1 & 0 & 1 & -2 \\
B-3 & 3 & 0 & 1 & 2 & -2 & -1 & 0 & -3 \\
B-0 & 6 & 3 & 4 & 5 & 1 & 2 & 3 & 0 \\
\hline
\end{tabular}

Table 8

\begin{tabular}{|l|c|c|c|c|c|c|c|c|}
\hline \multicolumn{1}{|c|}{ FROM JACK'S VIEWPOINT } \\
\hline & $\mathrm{J}-1.2 .3$ & $\mathrm{~J}-1.2$ & $\mathrm{~J}-1.3$ & $\mathrm{~J}-2.3$ & $\mathrm{~J}-1$ & $\mathrm{~J}-2$ & $\mathrm{~J}-3$ & $\mathrm{~J}-0$ \\
\hline B-1.2.3 & 0 & 1 & 2 & 3 & 3 & 4 & 5 & 6 \\
B-1.2 & -1 & 0 & 1 & 2 & 2 & 3 & 4 & 5 \\
B-1.3 & -2 & -1 & 0 & 1 & 1 & 2 & 3 & 4 \\
B-2.3 & -3 & -2 & -1 & 0 & 0 & 1 & 2 & 3 \\
B-1 & -3 & -2 & -1 & 0 & 0 & 1 & 2 & 3 \\
B-2 & -4 & -3 & -2 & -1 & -1 & 0 & 1 & 2 \\
B-3 & -5 & -4 & -3 & -2 & -2 & -1 & 0 & 1 \\
B-0 & -6 & -5 & -4 & -3 & -3 & -2 & -1 & 0 \\
\hline
\end{tabular}

Table 9

\begin{tabular}{|l|c|c|c|c|c|c|c|c|}
\hline \multicolumn{10}{|c|}{ PRODUCT OF PAY-OFFS } \\
\hline & $\mathrm{J}-1.2 .3$ & $\mathrm{~J}-1.2$ & $\mathrm{~J}-1.3$ & $\mathrm{~J}-2.3$ & $\mathrm{~J}-1$ & $\mathrm{~J}-2$ & $\mathrm{~J}-3$ & $\mathrm{~J}-0$ \\
\hline $\mathrm{B}-1.2 .3$ & 0 & -3 & -4 & -3 & -15 & -16 & -15 & -36 \\
$\mathrm{~B}-1.2$ & -3 & 0 & 1 & 4 & -4 & -3 & 0 & -15 \\
$\mathrm{~B}-1.3$ & -4 & $(1)^{*}$ & 0 & 1 & -3 & -4 & -3 & -16 \\
$\mathrm{~B}-2.3$ & -3 & $(4)$ & $(1)$ & 0 & 0 & -3 & -4 & -15 \\
$\mathrm{~B}-1$. & -15 & -4 & -3 & 0 & 0 & 1 & 4 & -3 \\
$\mathrm{~B}-2$ & -16 & -3 & -4 & -3 & $(1)$ & 0 & 1 & -4 \\
$\mathrm{~B}-3$ & -15 & 0 & -3 & -4 & $(4)$ & $(1)$ & 0 & -3 \\
$\mathrm{~B}-0$ & -36 & -15 & -16 & -15 & -3 & -4 & -3 & 0 \\
\hline
\end{tabular}

Table 10

*The bracketed pay-offs are positive products that result from the multiplication of two negative numbers. They represent losses for both parties, and hence cannot be considered as positive pay-offs in the search for the maximum pay-off. Plotted on a graph these bracketed pay-offs show up in the third quadrant (III).

A search through the product of pay-offs matrix to find the maximum products reveals that at (B-1.2, J-2.3) there is a pay-off of 4 ; also at $(\mathrm{B}-1, \mathrm{~J}-3)$ there is a pay-off of 4 . Both of these are, therefore, optimum solutions. Refer- 
ence to the parties' tables of alternative strategies ${ }^{11}$ to identify the specific trades these solutions represent reveals that $(\mathrm{B}-1, \mathrm{~J}-3)$ is train in exchange for pen, and (B-1.2, J-2.3) is train and car in exchange for pencil and pen. This is, of course, the same pair of optimum solutions that was obtained by the intuitive method.

\section{The Graphic Method}

Figure 2 results from plotting the pay-offs from the matrices of the individual parties' viewpoints. ${ }^{12}$ The point $(2,2)$ is the point in the diagonally shaded polygon in the first quadrant (I) that produces the largest rectangle when perpendiculars are dropped to the $X$ and $Y$ axes. This point is plotted from two different pairs of strategies of Bill and Jack. And these pairs of strategies turn out to be (B-1, J-3) and (B-1.2, J-2.3) -the same optimum solutions that were obtained by intuition and by the matrix method.

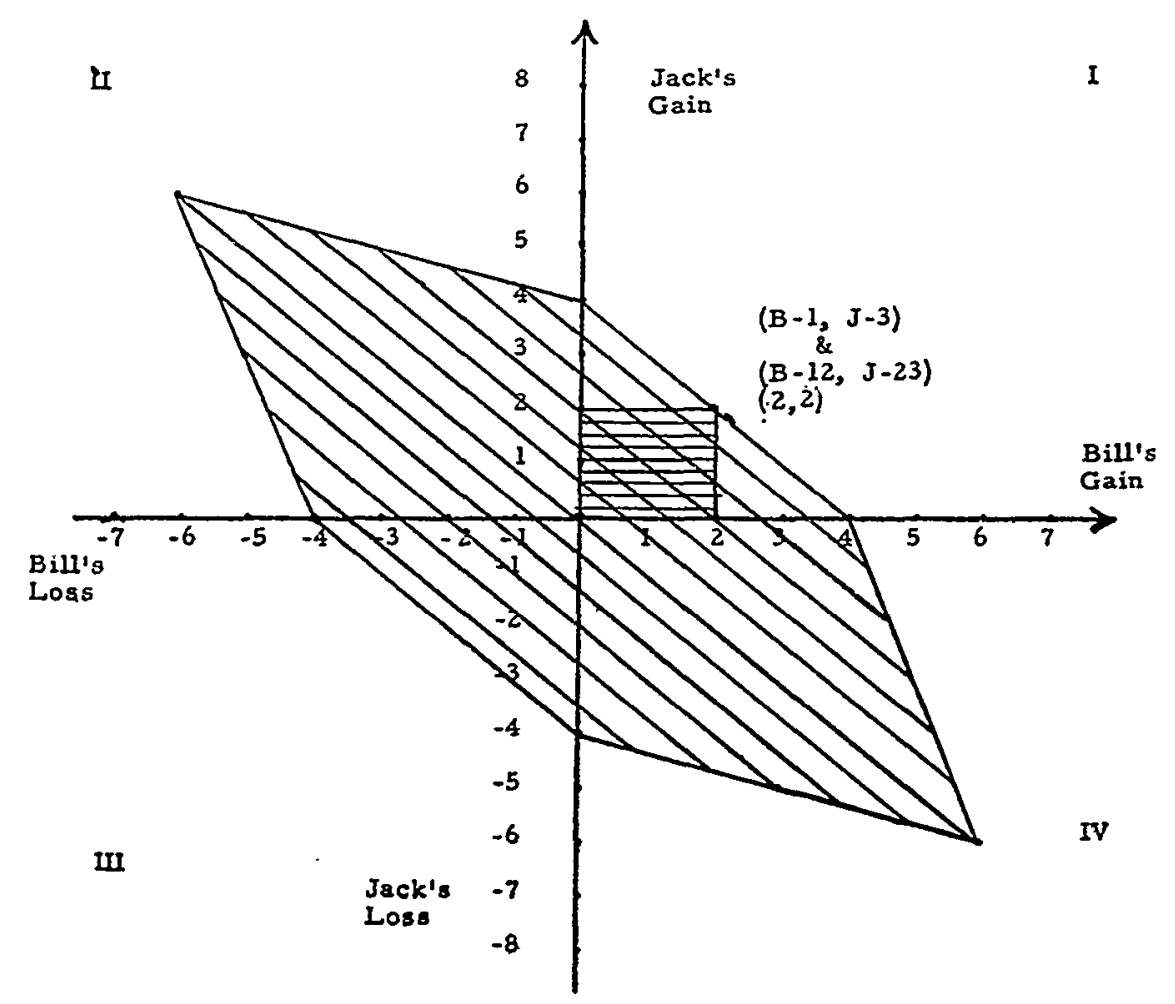

Figure 2

Now that the bargaining situations are increasing in complexity, it is appropriate to introduce another method of determining the optimum solution. This

11. P.667 supra.

12. Tables 8 \& 9 supra. 
method, whose advantage will later be apparent, will be given the appropriate if somewhat paradoxical tag, "systematic trial-and-error method."

\section{The Systematic Trial-and-Error Method}

The systematic trial-and-error method consists of the following steps:

STEP 1 Assume that party $A$ gives up all the items he possesses that party $B$ values higher than $A$ does, and that party $B$ gives up all the items he possesses that party $A$ values higher than $B$ does. Compute the product of $A$ 's gains and $B$ 's gains from such a trade.

SteP 2 If in STEP 1 one party receives a greater gain than the other party, the party with the greater gain gives to the party with the lesser gain those items now in the greater beneficiary's possession that both parties value equally. The greater beneficiary should give up the equally valued item or combination of such items that most nearly closes the gap between the parties' gains, or the parties should exchange the combination of equally valued items that most narrows the gap.

STEP 3 If after the equally valued items have been given over in STEP 2 there is still a discrepancy between the parties' gains, the greater beneficiary will give up items now in his possession that he values more than the lesser beneficiary does. In general, the first items to be tried will be those on which the difference in the parties' valuation is least, working up the scale towards those on which the difference is greatest.13 After each item changes hands, the product of gains is again computed and compared with previous products. When the product ceases to rise, the optimum solution has been determined. . $^{\text {t4 }}$

13. The objective of the third step, as of the second, is to reduce the gap between the parties' gains, but at the same time to minimize the loss in the sum of the parties' gains. The items to be considered in STEPS $2 \& 3$ would, therefore, generally be only those for which the total of the parties' valuations is no larger than the gap remaining to be closed.

The basis for trying to equalize the parties' gains is that when the sum of the two gains is constant the greatest product of gains will be achieved when the gains are most nearly equal. See note 8 supra. But in STEP 3 each move will reduce the sum of the parties' gains (since the giving party loses more units of satisfaction than the receiving party gets), and in so doing may either reduce or enlarge the product of the gains. Of course, the only items the Bargain Solver will want to consider in STEP 3 will be those which will increase the product even though they decrease the sum.

If the gap between the parties' gains following STEP 2 is small, and there are a limited number of items that will fit in the gap, there should be no dificulty about swiftly identifying the items to be tried in STEP 3. If, however, there is still a large gap, and there are a good many items of the right size still untraded, then it may require either art or extensive effort on the part of the Bargain Solver to determine which items or combinations of items will enlarge the product and which will reduce it. Suffice it to say for present purposes that trial-and-error would discover the right result, and that short cuts could be readily devised.

14. There may, of course, be two or more optimum solutions, see text at note 9 supra, which will appear during the systematic trial-and-error calculations as two or more products of gains that are equal to each other but larger than the rest. 
If during STEP 3 the party who was lesser beneficiary becomes the greater beneficiary, then STEP 2 is repeated, starting from the point where this change occurred.

The details of this method will become clear when it is applied; for the moment, the essential point to grasp is that the objective is to find the solution that gives each party the most nearly equal gains, and which at the same time maximizes the product of the gains. This solution will be the optimum solution.

For the moderately complex bargaining situation at hand, the systematic trial-and-error method is illustrated in Table 11.

\begin{tabular}{|c|c|c|c|c|c|c|c|c|c|}
\hline & \multicolumn{2}{|c|}{ SOLUTION } & \multicolumn{3}{|c|}{ Bill } & \multicolumn{3}{|c|}{$\mathrm{J}_{\mathrm{ACK}}$} & \multirow[b]{2}{*}{ Product } \\
\hline & $\begin{array}{c}\text { Bill } \\
\text { Gives }\end{array}$ & $\begin{array}{l}\text { Jack } \\
\text { Gives }\end{array}$ & Loss & Gain & Net & Loss & Gain & Net & \\
\hline STEP 1 & & & & & 1 & & & & \\
\hline $\begin{array}{l}\text { Each party gives } \\
\text { up items that the } \\
\text { other party values } \\
\text { more. }\end{array}$ & B-1 & $\mathrm{J}-3$ & 1 & 3 & 2 & 1 & 3 & 2 & 4 \\
\hline STEP 2 & & & & & & & & & \\
\hline $\begin{array}{l}\text { Party with greater } \\
\text { gain gives away }\end{array}$ & B-1.2 & $\mathrm{J}-3$ & 3 & 3 & 0 & 1 & 5 & 4 & 0 \\
\hline $\begin{array}{l}\text { his equally valued } \\
\text { items one at a } \\
\text { time. Here both } \\
\text { parties have same } \\
\text { gain so arbitrarily } \\
\text { start with one. } \\
\text { Compare products. }\end{array}$ & B-1.2 & $J-2.3$ & 3 & 5 & 2 & 3 & 5 & 2 & 4 \\
\hline SteP 3 & & & & & & & & & \\
\hline $\begin{array}{l}\text { Party with greater } \\
\text { gain gives away } \\
\text { his items which he } \\
\text { values more than } \\
\text { the other party } \\
\text { does. Again both } \\
\text { parties have same } \\
\text { gain so arbitrarily } \\
\text { start with one. } \\
\text { Compare products. }\end{array}$ & B-1.2.3 & $\mathrm{J}-2.3$ & 6 & 5 & -1 & 3 & 6 & 3 & -3 \\
\hline $\begin{array}{l}\text { (Note that if STEP } \\
3 \text { is begun by tak- } \\
\text { ing items from } \\
\text { Jack instead of Bill, } \\
\text { the result is the } \\
\text { same.) }\end{array}$ & B-1.2 & $\mathrm{J}-1.2 .3$ & 3 & 6 & 3 & 6 & 5 & -1 & -3 \\
\hline
\end{tabular}

Table 11

Comparison of the products in the last column reveals that the product was a maximum at STEP 1, in which Bill gave up B-1, the train, and Jack gave up J-3, the pen. The next trade, in STEP 2, was Bill's giving up his equally 
valued item $B-2$, the car, which diminished the product to 0 . However, when the next equally valued item, J-2, the pencil, was given up by Jack, the product again was 4. In STEP 3, with Bill giving up B-3 (or Jack giving up J-1), the product declined once more. The product is maximized at two points: one where the transaction ( $\mathrm{B}-1, \mathrm{~J}-3$ ) has taken place; the other where the transaction (B-1.2, $\mathrm{J}-2.3$ ) has occurred. These are the optimum solutions found by the systematic trial-and-error method, and, as has been seen, by the other methods as well.

In this bargaining situation, which is only slightly complex, it is already apparent that the systematic trial-and-error method affords a substantial calculational advantage over the matrix and graphic methods of obtaining the optimum solutions. This calculational advantage becomes increasingly important as the bargaining situation gets more complex.

\section{A Complex Bargaining Situation}

Once again assume two individuals, Bill and Jack, intelligent, free to trade, and each seeking to improve his position. Suppose they possess and value certain items as follows: 15

\begin{tabular}{|c|c|c|c|}
\hline & Bill's Items & Bill's Valuation & Jack's Valuation \\
\hline $\mathrm{B}-1$ & Book & 2 & 4 \\
\hline $\mathrm{B}-2$ & Whip & 2 & 2 \\
\hline$B-3$ & Ball & 2 & 1 \\
\hline B- 4 & Bat & 2 & 2 \\
\hline B- & Box & 4 & 1 \\
\hline
\end{tabular}

$\begin{array}{llrl} & \text { Jack's Items } & & \\ \text { J-1 } & \text { Pen } & 10 & 1 \\ \text { J-2 } & \text { Toy } & 4 & 1 \\ \text { J-3 } & \text { Knife } & 6 & 2 \\ \text { J-4 } & \text { Hat } & 2 & 2\end{array}$

\section{The Intuitive Method}

Here, once again, is a bargaining situation that is quickly recognized as ripe for a trade. It is clear that there should be some trade between Bill and Jack, for both parties will gain from an exchange of various items. But what items? Who should give up what, and expect to get what in return? The optimum solution to this problem is not one that is intuitively obvious. ${ }^{16}$ It is apparent that as the complexity of the situation increases, the intuitive method for finding the optimum solution grows increasingly inadequate; when the degree

15. This example is taken from Nash, supra note 2, at 161 .

16. In order to get some indication of the obviousness of the optimum solution, the author submitted this bargaining situation to a random group of persons with higher than average educational qualifications. None of the group was familiar with the matrix, 
of complexity of the bargaining has reached some point, the intuitive method will no longer work at all.

\section{The Matrix Method}

Since Bill owns five items, he has open to him 32 different strategies:

$\begin{array}{llll}\text { B-1.2.3.4.5 } & \text { B-1.2.5 } & \text { B-1.2 } & \text { B-3.5 } \\ \text { B-1.2.3.5 } & \text { B-1.3.4 } & \text { B-1.3 } & \text { B-4.5 } \\ \text { B-1.2.3.4 } & \text { B-1.3.5 } & \text { B-1.4 } & \text { B-1 } \\ \text { B-1.2.4.5 } & \text { B-1.4.5 } & \text { B-1.5 } & \text { B-2 } \\ \text { B-1.3.4.5 } & \text { B-2.3.4 } & \text { B-2.3 } & \text { B-3 } \\ \text { B-2.3.4.5 } & \text { B-2.3.5 } & \text { B-2.4 } & \text { B-4 } \\ \text { B-1.2.3 } & \text { B-2.4.5 } & \text { B-2.5 } & \text { B-5 } \\ \text { B-1.2.4 } & \text { B-3.4.5 } & \text { B-3.4 } & \text { B-0 }\end{array}$

Sinilarly, Jack with four items has the following 16 strategies open to him:

$\begin{array}{llll}\mathrm{J}-1.2 .3 .4 & \mathrm{~J}-2.3 .4 & \mathrm{~J}-2.3 & \mathrm{~J}-2 \\ \mathrm{~J}-1.2 .3 & \mathrm{~J}-1.2 & \mathrm{~J}-2.4 & \mathrm{~J}-3 \\ \mathrm{~J}-1.2 .4 & \mathrm{~J}-1.3 & \mathrm{~J}-3.4 & \mathrm{~J}-4 \\ \mathrm{~J}-1.3 .4 & \mathrm{~J}-1.4 & \mathrm{~J}-1 & \mathrm{~J}-0\end{array}$

Because Bill has 32 and Jack 16 different strategies, there are a total of 512 different solutions in this bargaining situation. Each of the three matrices will, therefore, require 512 calculations. The tedium of making all these computations to solve a bargaining problem of only moderate complexity suggests that the matrix method is too cumbersome a technique for obtaining the optimum solution.

When the necessary 1536 calculations ${ }^{17}$ to construct the three matrices have been made, however, and the product of pay-offs matrix is examined, the maximum pay-off turns out to be 60 , at (B-1.2.3.4, J-1.2.3). This means that the optimum solution in this bargaining situation is for Bill to trade his book, whip, ball and bat for Jack's pen, toy and knife. ${ }^{18}$ If this deal is consummated,

the graphic or the systematic trial-and-error methods for obtaining optimum solutions. None of them could figure out what the trade should be, although they were all convinced that some trade should take place.

The reader who attempts to guess the optimum solution may, of course, find himself more intuitively accurate than the members of this random group; he can check his solution below at p. 674 .

17. These calculations were worked out by the author, but did not seem to warrant the three pages of print their inclusion here would require.

18. To the games theorist this declaration will seem strange. In Theory of Games jargon this solution represents the best "pure strategy" solution. The writer is aware that the best "mixed strategies" solution for this example is the one that employs a random device that will select the solution (B-1.2.3.4, J-1.2) seven times for every one time that (B-1.2.3.4, $\mathrm{J}-1.2 .3$ ) is selected, thereby attaining the maximum possible gains for each party over the long run. "Mixed strategies" solutions are not considered here for two 
Bill will wind up with a total of 24 units of satisfaction where he started out with 12 , for a net gain of 12 units; and Jack will ultimately have 11 units from a start of 6 , for a net gain of 5 .

\section{The Graphic Method}

Like the matrix method, the graphic method is far too cumbersome for practical use in a bargaining situation of this complexity. It requires the plotting of 512 points-or at least a goodly portion of that number. ${ }^{10}$ The effort would achieve the correct result, but the systematic trial-and-error method will achieve the same result at an enormous saving of time and effort.

\begin{tabular}{|c|c|c|c|c|c|c|c|c|c|}
\hline & \multicolumn{2}{|c|}{ SoLutron } & \multicolumn{3}{|c|}{ BrLL } & \multicolumn{3}{|c|}{$J_{A C K}$} & \multirow{2}{*}{$\begin{array}{l}\text { Prod- } \\
\text { UCT }\end{array}$} \\
\hline & $\begin{array}{c}\text { Bill } \\
\text { Gives }\end{array}$ & $\begin{array}{l}\text { Jack } \\
\text { Gives }\end{array}$ & Loss & Gain & Net & Loss & Gain & Net & \\
\hline \multicolumn{10}{|l|}{ STEP 1} \\
\hline $\begin{array}{l}\text { Each party gives } \\
\text { up items that the } \\
\text { other party values } \\
\text { more. }\end{array}$ & B-1 & $\mathrm{J}-1.2 .3$ & 2 & 20 & 18 & 4 & 4 & 0 & 0 \\
\hline STEP 2 & & & & & & & & & \\
\hline $\begin{array}{l}\text { Party with greater } \\
\text { gain gives away }\end{array}$ & B-1.2 & $\mathrm{J}-1.2 .3$ & 4 & 20 & 16 & 4 & 6 & 2 & 32 \\
\hline $\begin{array}{l}\text { his equally valued } \\
\text { items. Compare } \\
\text { products. }\end{array}$ & B-1.2.4 & $\mathrm{J}-1.2 .3$ & 6 & 20 & 14 & 4 & 8 & 4 & 56 \\
\hline STEP 3 & & & & & & & & & \\
\hline $\begin{array}{l}\text { Party with greater } \\
\text { gain gives away } \\
\text { his items which he }\end{array}$ & $\begin{array}{c}\mathrm{B}-1.2 .3 \\
.4\end{array}$ & $\mathrm{~J}-1.2 .3$ & 8 & 20 & 12 & 4 & 9 & 5 & 60 \\
\hline $\begin{array}{l}\text { values more than } \\
\text { the other party } \\
\text { does. Compare } \\
\text { products. }\end{array}$ & $\begin{array}{r}\mathrm{B}-1.2 .3 \\
.4 .5\end{array}$ & $\mathrm{~J}-1.2 .3$ & 12 & 20 & 8 & 4 & 10 & 6 & 48 \\
\hline
\end{tabular}

Table 12

reasons: first, for simplicity's-sake; and second, because collective bargaining agreements can probably be made to include a wage adjustment item or another such item that will in effect enable "side payments" to be made in a common medium of exchange, equalizing the gains of the parties in a single bargain. See note 33 infra. Nash has demonstrated that whenever this is possible, the problem takes on an especially simple form. "Mixed strategies" solutions are no longer necessary, and the optimum solution will be a "pure strategy" solution. Nash, supra note 2, at 166-67. For these reasons it seems convenient and permissible to gloss over "mixed stategies" theory for present purposes, and to label the best "pure strategy" solutions for the various problems the "optimum" solutions-realizing the while that strictly speaking they may not always be the "optimum" solutions in the terminology of the Theory of Games.

19. Nash has plotted the important segment of this situation (that occurring in the first quadrant) in his article, supra note 2, at 161. 


\section{The Systematic Trial-and-Error Method}

A comparison of the products in the last column in Table 12 reveals that the product was at 60 when Bill gave up B-3 in STEP 3. The further giving up of B-5 by Bill produced a decline in the product. Hence, the product is a maximum when the transaction (B-1.2.3.4, J-1.2.3) takes place (book, whip, ball and bat exchanged for pen, toy and knife). This is the optimum solution found rather easily by the systematic trial-and-error method. It is the same optimum solution as found by both the matrix method and Nash's graphic method. ${ }^{20}$

Hereinafter, when it is necessary to find the optimum solution to a bargaining situation it will be done by means of the systematic trial-and-error method only. Full confidence is warranted, however, that the results will be the same as would be achieved by the matrix and graphic methods.

\section{The Single Scale of Valuation}

Before the Nash technique is applied to a collective bargaining hypothetical, a fundamental characteristic of the system should be pointed out: it does not matter whether or not the parties are operating on the same valuation scale in "pricing" the items involved in the bargain. Even if they are evaluating items in completely different units, the resulting optimum solution will be the same as it would be if they had evaluated in the same units. The optimum solution is determined by the internal ratio of each party's bids to his other bids, and is unaffected by differences in scale between the parties.

Assume, for example, in the most complex Bill-Jack situation, that the parties had both been evaluating in terms of nickels. Now consider what would have happened if Bill had evaluated in terms of pennies while Jack still evaluated in nickels. The situation would then be as follows:

\begin{tabular}{lllc}
\multicolumn{2}{c}{ Bill's Items } & Bill's Valuation & Jack's Valuation \\
\cline { 2 - 3 } B-1 Book & $2 \times 5=10$ & 4 \\
B-2 Whip & $2 \times 5=10$ & 2 \\
B-3 Ball & $2 \times 5=10$ & 1 \\
B-4 Bat & $2 \times 5=10$ & 2 \\
B-5 Box & $4 \times 5=20$ & 1
\end{tabular}

\section{Jack's Items}

$\begin{array}{llrl}\text { J-1 } & \text { Pen } & 10 \times 5=50 & 1 \\ \text { J-2 } & \text { Toy } & 4 \times 5=20 & 1 \\ \text { J-3 } & \text { Knife } & 6 \times 5=30 & 2 \\ \text { J-4 } & \text { Hat } & 2 \times 5=10 & 2\end{array}$

20. Ihid. 
The systematic trial-and-error method is applied to this situation in Table 13.

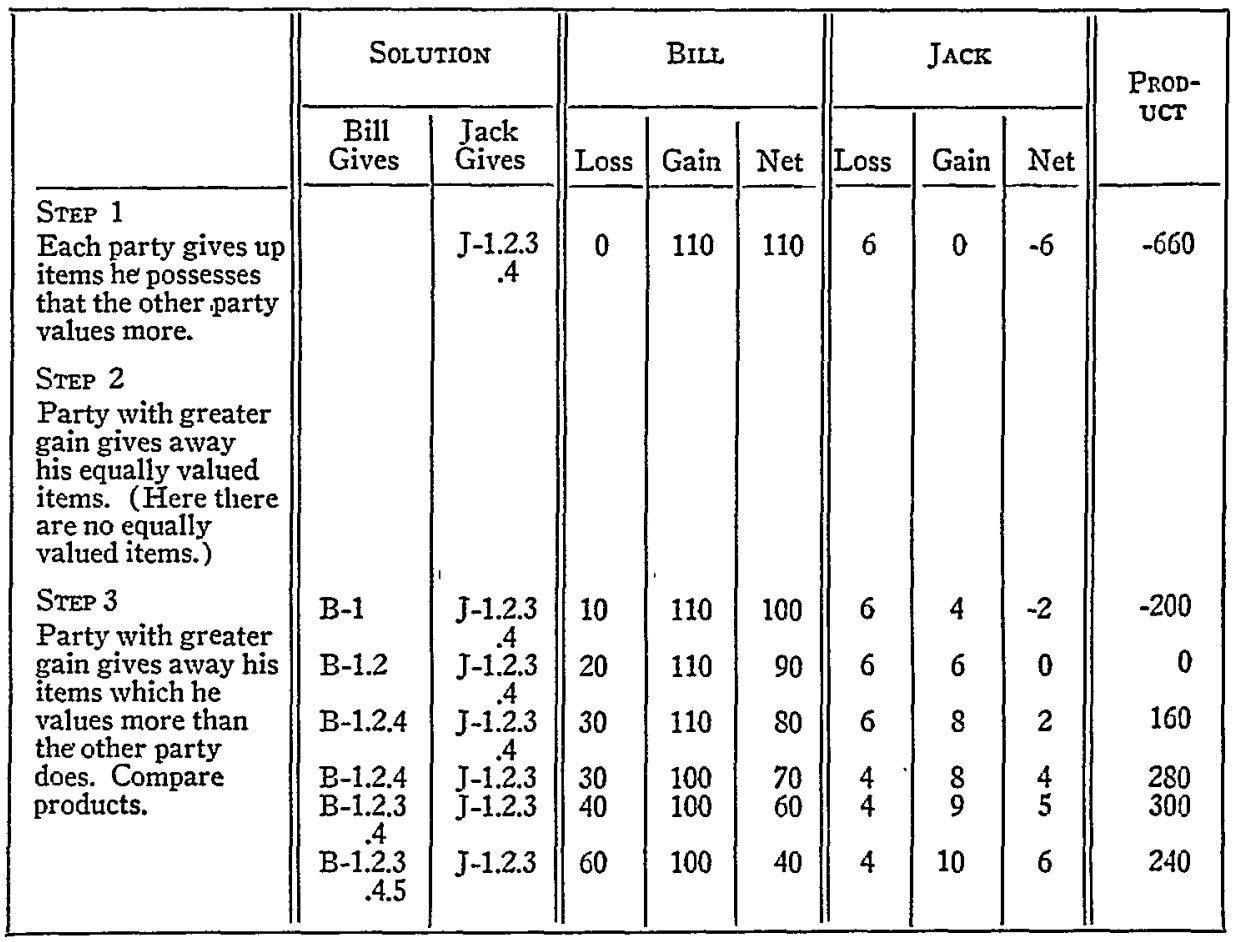

Table 13

The optimum solution to this situation when the parties are evaluating in different units turns out to be B-1, B-2, B-3, and B-4 in exchange for J-1, J-2 and $\mathrm{J}-3$. This is the same solution that was derived when the parties were assumed to be evaluating in the same units of value. ${ }^{21}$ Although this may seem to be a somewhat startling characteristic of the optimum solutions derived by this technique, it is nevertheless universally true. It simply does not matter whether the parties evaluate in the same units; the results are not affected. ${ }^{22}$

\section{A New Franiework for Collective Bargaining}

The similarities of labor-management collective bargaining to the BillJack situations discussed so far should be apparent. There are two parties in the situation, both able to trade for their mutual benefit, and each seeking to maximize his gains and minimize his losses. Each has certain items that the other would like- a labor demand for a wage increase, for instance, is essentially a demand for an item that management possesses and can offer in trade. And

21. See p. 674 supra.

22. In some circumstances a single scale of valuation may in fact be necessary. See note 33 infra. If necessary, such a single scale can easily be obtained merely by converting the parties' evaluations into percentages. 
the items in dispute in collective bargaining are items on which the parties put differential, even though perhaps not explicit, valuations. But in ordinary collective bargaining there is an elaborate, devious and often emotionalized process of offer and counteroffer. The bargaining eventually arrives, with luck, at a solution that is acceptable to the parties, but never at one that is guaranteed to be the best of possible solutions for both parties. By contrast, in the Bill-Jack situations an optimum solution was arrived at swiftly, precisely and dispassionately. The advantages of the Bill-Jack solution were due to the use of the Nash technique; why should not this technique be applicable to collective bargaining as well?

It can be done; but it requires first a setup that will put the collective bargaining situation into a form to which the Nash technique can be applied, and then certain adjustments for the transfer from hypothetical example to flesh-andblood reality.

\section{A Ganes Bargaining Setup}

The working out of the optimum solution to a collective bargaining situation by means of the Nash technique could be put in the hands of a disinterested third party who might be designated the "Bargain Solver." His would be the function of collating the lists of the items offered and requested by each side, getting evaluations put upon each item by both of the parties, and then calculating the optimum solution. Specifically, the Bargain Solver would go through three steps: Step A: Requiring each party to submit as many requests and offers as possible, so as to have a large number of items in the bargaining situation. This step expands the scope of the bargaining. Step B: Compiling lists of all the items that have been put into the bargaining, and requiring each party to put relative valuations upon each item. Once made, these valuations could not be changed by the parties; and neither party would know until the Games Bargaining was completed what valuations the other party had put on the items. STEP C: Computing the optimum solution by means of the systematic trial-anderror method.

The parties would, as in present-day labor arbitration, make a submission agreement, agreeing to be bound by the results of the Games Bargaining. ${ }^{23}$ But the Bargain Solver would not be invested with the kind of power exercised by an arbitrator, for he would not wield in the parties' stead any utilmate power of decision. His functions would be essentially only mechanical, administrative ones. During the bargaining the parties would be unable

23. Ideally, such a submission agreement would be made. There is, however, no reason why Games Bargaining could not be used as an entirely mediatory device, with the solution having no binding force whatsoever. The parties might agree only that they will negotiate by Games Bargaining to see what solution it will crank out, reserving the right to accept or reject the solution. In fact, it is probably reasonable to expect that any initial efforts to experiment with such a system for bargaining would be undertaken on this basis. If a workable system of Games Bargaining evolves, parties are then likely to be more willing to accept submission agreements. 
to change the valuations they had put upon the items; to this extent the parties would relinquish their ability to manipulate the bargaining. But after the solution was reached both would be able to check thoroughly every motion that the Bargain Solver had made.

The Bargain Solver would be in a position somewhat like that of an auctioneer, in an auction where (a) there are only two parties participating in the bidding, (b) the two bidding parties are restricted to one bid on each item, (c) the bids on each item are given secretly and simultaneously, and (d) the two bidding parties have contributed all the items to be auctioned.

A crucial feature of this Games Bargaining auction is the bidding-that is, the evaluation by each party of all the items that may be traded. The problem of evaluation is a major hurdle to be cleared, and one that requires special examination.

\section{Evaluation of the Items to be Traded}

Games Bargaining depends entirely upon the parties' being able to put accurate numerical valuations upon every item in the situation. Yet it may well be objected that neither labor nor management could put exact price tags upon the sort of things that are involved in collective bargaining; and some scholars insist that it is usually impossible to quantify such items in comparable units. $^{24}$ To these grave objections it is possible to essay several tentative answers. ${ }^{25}$

In the first place, only comparative, not absolute, valuations are necessary. As has been seen, the parties need not use the same valuation scale. ${ }^{20}$ Thus, although a dollar scale might be more familiar and so more convenient, it would by no means be necessary. A party need only establish the relative worth for him of each item to some other item, and express that relationship numerically, with or without a dollar sign. Again, even in present collective bargaining the parties or the arbitrators do of necessity make comparative valuations of the items in dispute. Whether or not expressed in numerical terms, preference judgments must be made in order for any bargain to be reached.

Furthermore, to the objection that values of this sort cannot be quantified, Bross has answered:

"[M]any of the quantities which we now regard as being measured fairly well were formerly considered to be unmeasurable. Just a century ago it would have seemed absurd to claim that the intelligence of a person could be stated as a number. Today numerical measures of intelligence are commonplace and-what is more important-are used to make practical decisions in the employment of personnel."27

24. Dahl \& Lindilon, Politics, Economics and Welfare 81 (1953).

25. In addition to the problem of getting accurate evaluations from the parties, there is the separate but related problem of getting honest evaluations. This problem is discussed at pp. 688-91 infra.

26. See pp. 675-76 supra. But cf. note 33 infra.

27. Bross, Design for Decision 86 (1953). 
Further progress in the quantification of values is not an empty hope. Shapley and Shubik have succeeded in designing a technique for quantifying the distribution of power as determined by the formal structure of an organization. ${ }^{28}$ Does this not also represent the quantification of something that previously would have been generally regarded as unmeasurable?

Finally, if the problem of giving numerical valuation to some items remains insuperable at present, still there may be other items that the parties can put relative price tags on ; if so, Games Bargaining can now be employed at least with those quantifiable items.

These answers are all speculative; but so, in fact, is the question. Until an employer and a union have set themselves to the problem of evaluating the items in an actual collective bargaining situation, there is no way of knowing how well they will fare. An ounce of trial would be worth a pound of speculation.

\section{Expanding the Scope of the Bargain}

There remains for preliminary discussion the element that has been added to the Theory of Games foundation in order to make the basic framework of the system outlined in this comment. Simply put, Games Bargaining is designed to bring as many items as possible into the bargaining situation. This is not necessary to the working out of the optimum solution, but it does tend to increase the satisfaction that each party will get out of the optimum solution. The more items there are to be traded, the more likely a trade is to occur, and the broader and more satisfactory that trade is likely to be.

Furthermore, a broader scope to the bargaining should shift the context of the negotiations somewhat, from grounds that may have become encrusted with emotion by constant dispute, to new grounds where hard-and-fast positions have not been taken and where new and unexpected satisfactions may arise. In this sense, broadening the scope of the bargain tends to produce what Lasswell and McDougal have called an "integrative solution":

"When each party can recognize its gains or losses in a controversy, we speak of compromise solutions. A standard example is splitting the difference between the high and low bid in a wage negotiation. There is, however, another type of solution which is characterized by the fact that the parties are unable to distinguish what they have 'won' or 'lost.' Such a solution is integrative. In industrial relations an integrative solution is sometimes achieved in which a new framework of co-operation comes into being, and old bargaining points are no longer revived. Sometimes an arrangement is devised for joint management participation, or for a profit sharing split in the annual take.

“Integrative solutions are continually being exemplified in smoothly operating families. New adjustments are made as children grow and parents decline. At any given level of equilibrium a system of compromise works well. If it is understood that everybody is to help in the household chores, a dispute may arise as to who makes the beds, or sweeps the floor,

28. Shapely \& Shubik, A Method for Evaluating the Distribution of Pozver in a Committec System, 48 Aar. PoL. Scr. Rev. 787 (1954). 
or cleans up the bathroom. The problem may be settled by working out a definite schedule of duties designed to equalize both the time involved and the burden of the most disagreeable assignments. Minor disagreements are compromised within this framework. After operating smoothly for a while, however, this scheme may produce complaints and recriminations to a disruptive degree; it is time for a change, for a more contextual view to be taken. The gripes about the rules can be treated as symptoms of a growth process which has generated so many new perspectives that older compromises have become provocations. This situation may now be re-defined by giving each child a separate room, and making him wholly responsible for keeping it in shape and improving it. Squabbles about the older division of labor are now obsolete. Within the new framework energies find sources of gratification that were unattainable within the previous equilibrium. As issues arise in the new context they are at first compromised. When the compromises become sources of strife, a new stage of growth has arrived, and a new integration is needed."20

\section{Games Bargaining In Action}

Now the time has come to delineate in detail the system of Games Bargaining against the background of a hypothetical collective bargaining situation.

\section{Hypothetical Bargaining Situation: Dispute in the Vehicle Industry}

After five years of comparative tranquillity in the collective bargaining of Management and Labor of American Vehicles Inc., some accumulated desires of both parties have risen to the surface as the deadline approaches for the negotiation of a new basic contract. Technological advances during the last half decade have made it clear that the automation of production in various areas of the vehicle industry is more than just a remote possibility. In fact, Management of AVI believes that it is already technologically feasible for an important segment of AVI's production, the construction of engine heads, to be done by automation. To have engine heads built by machines that are entirely controlled by other machines would bring great savings in cost-savings in labor cost. Management is naturally anxious to have its Assembly Line $B$, where the engine heads are constructed, switched over to an automation system. The union, however, takes a somewhat less enthusiastic view, being apprehensive about the fate of the 2500 men who now work on Assembly Line $B$.

Management has another desire which it makes known. There has never been anything said in the basic agreement between Management and Labor about washing-up-about whether or not this shall be done on company time or on the worker's own time. Prewar custom over the years had been that the workers were excused five minutes before quitting time in order to get cleaned up before going home. But during the war, when there was a general laxity of discipline, the workers had eased into the habit of knocking off fifteen to twenty minutes before quitting time to wash up. Management had said nothing about it at that time (contracts were then all for the government, on a

29. Lasswell \& MicDougal, supra note 4, at 167-68. 
cost-plus basis), and the practice continued into the postwar period. Immediately after the war there was a seller's market in the vehicle industry and profits were high; this perhaps accounted for Management's failure to seek any modification of the fifteen to twenty minute wash-up practice. But now competition has become very keen in the vehicle industry and Management is casting about for ways to reduce costs. Consequently, Management now seeks to reach a definite understanding in the collective bargaining agreement that wash-up time shall be five minutes-and no more. The union has a somewhat different perspective on this question also.

The union leaders, in turn, have been biding their time until the present contract expired. Over the years workers in the vehicle industry have suffered from periodic layoffs. Fluctuations in the economy and the whims of consumers of vehicles are sharply reflected in the vehicle market, with the result that there are frequent interruptions in production, and consequent layoffs of production workers. The union does not see why workers should bear the cost of such interruptions. Therefore, it seeks what it calls a "Guaranteed Employment Plan." The union proposes that when a man is laid off, the company should pay him supplementary unemployment compensation benefits. An unemployed worker would collect benefits from both the state and his employer. The union wants such a plan embodied in the next bargaining agreement. Management of AVI, of course, wants no part of any such guaranteed annual wage scheme.

But that is not all the union wants. Retirement benefits for AVI employees have proved to be woefully inadequate in the light of postwar inflation and the high cost of living. And so the union would also like a substantial increase in the company's contribution to the workers' pension plan.

When the parties gather around the bargaining table the lines are clearly drawn :

$$
\text { Management Requests }
$$

MR-1 Automation of Assembly Line $B$

MR-2 Five-minute Wash-up

\section{Labor Requests}

LR-1 Guaranteed Employment Plan

LR-2 Increased Pension Benefits

The bargaining that results is spirited, but progress is slow. Management makes the first offer, proposing an even swap-LR-1 and LR-2 in exchange for MR-1 and MR-2. But Labor will not go along with such a trade because it feels that giving up MR-1 and MR-2 is worth too much compared with what it will receive in return. The reason for Labor's reluctance would become apparent if Labor's evaluations of the four items in dispute were expressed numerically. Suppose, for example, that Labor considers the Guaranteed Employment Plan (LR-1) worth 18 units of satisfaction; $;^{30}$ and relative to LR-1 and in the same units of satisfaction, the other items are worth:

30. These units nay represent a million dollars each, if the parties find that a convenient and familiar unit of value to think in terms of, but it is not essential that the 


$\begin{array}{lr}\text { LR-2 } & 6 \text { units } \\ \text { MR-1 } & 23 \text { units } \\ \text { MR-2 } & 2 \text { units }\end{array}$

In the trade suggested by Management, Labor would give up 25 units $(23+2)$ but receive only 24 units $(18+6)$ in return.

On the other hand, it is easy to understand Management's enthusiasm for such a trade, if it is assumed that Management's relative evaluation of the items is:

$\begin{array}{lr}\text { LR-1 } & 19 \text { units } \\ \text { LR-2 } & 6 \text { units } \\ \text { MR-1 } & 35 \text { units } \\ \text { MR-2 } & 7 \text { units }\end{array}$

Management would net a gain of 17 units from the deal it has proposed: it would give up 25 units $(19+6)$ in exchange for 42 units $(35+7)$.

It is not hard to see why Labor would balk at such a trade, and unless further offers were forthcoming the bargaining process would soon reach a stalemate. At this point, however, the parties call upon the Bargain Solver, agreeing to conduct their negotiations through him and to abide by the result of the Games Bargaining procedure.

\section{The Games Bargaining Procedure}

STeP A: The Bargain Solver's first move would be to expand the scope of the bargaining, by requiring each party to add to the number of items subject to trading. Each party makes a list of all the items that it would lilie to receive from the other. In addition to these request items, each party should also make a list of items controlled by it that could be offered in exchange. The Bargain Solver might require a minimum total number of items from each party-say, three requests and two offers; but he would encourage each to make as many requests and offers as it could. Each party should be especially encouraged to request items that it thinks it values more than the other party does, and to offer items that it thinks the other party will value more than it does itself.

In addition to the items that the parties voluntarily suggest (both offers and requests), the Bargain Solver might have authority both to compel the parties to make further suggestions and to make suggestions himself, if he felt that there were not enough items in the bargaining situation. The more items the

unit be in dollar terms. It may be an entirely arbitrary figure, not representing any unit of value at all; still the solution derived by the systematic trial-and-error method will be the optimum solution so long as the valuations of the other items are accurately related to the arbitrarily selected figure for the first item. The reason why a complctely arbitrary unit still works is that it is not necessary for the two parties to make their valuations in the same unit of value. As was shown in the most complex Bill-Jack situation, varying the scale of one party's valuations has no effect on the optimum solution derived. See pp. 675-76 supra. A common unit of valuation would be necessary in certain instances, however. See note 33 infra. 
better, for not every item suggested will be traded. Each of the parties retains the power to reject suggestions made by the Bargain Solver, by the other party or even by itself-simply by means of the valuation that it places upon each item.

In the negotiations between Labor and Management of AVI, at the behest of Bargain Solver, Labor makes the following list:

\section{Labor Requests}

LR-1 Guaranteed Employment Plan

LR-2 Increased Pension Benefits

LR-3 Hourly Wage Increase of $\$ .12$

LR-4 Group Insurance Plan

LR-5 Christmas Bonus

LR-6 Extension of Vacation Benefits to Employees Who Have Been with AVI for One Year

LR-7 Check-off for the Collection of Union Dues.

\section{Labor Offers}

LO-1 A Modification in the Grievance Procedure That Management Has Been Seeking

L.O-2 Addition to the Disciplinary Rules of a Proviso Authorizing Disciplinary Measures for Wilful or Careless Destruction of Company Property (a rule that Management has been wanting)

LO-3 Installation of a System of Promotion by Merit to Replace the Present Rigid Seniority Promotion System

LO-4 Agreement to Permit a Time and Motion Study of the Big Lincolac Velicle Plant (a study Management has been wanting to make)

LO-5 Automation of Assembly Line $D$ (Doors and Fittings)

And Management submits the following list:

\section{Management Requests}

MR-1 Automation of Assembly Line $B$

MR-2 Five-minute Wash-up

MR-3 Co-operation with Job Reclassification in M Plant

\section{Management Offers}

MO-1 College Scholarship Program for Sons and Daughters of AVI Workers

MO-2 Incentive Plan for the Workers in $S$ Plant

Feeling that the scope of the bargain is sufficiently broad at this point, Bargain Solver finds it unnecessary to compel either of the parties to expand its list of requests and offers, or to add more suggested items himself.

STEP B: Bargain Solver's next step is to compile a master list of all the iterns in the situation and submit this to the parties to have them evaluate each item relative to the other items on the list. Labor and Management have already evaluated LR-1, LR-2, MR-1 and MR-2. Relative to these items already evaluated, they evaluate the remaining items as follows: 


\begin{tabular}{l}
$\begin{array}{l}\text { Items "Possessed" } \\
\text { by Labor }\end{array}$ \\
\hline MR-1 \\
MR-2 \\
MR-3 \\
LO-1 \\
LO-2 \\
LO-3 \\
LO-4 \\
LO-5
\end{tabular}

Items "Possessed"

by Management

LR-1
LR-2
LR-3
LR-4
LR-5
LR-6
LR-7
MO-1
MO-2

Labor's
Valuations

23

2

4

7

4
5

3

12
Management's

Valuations

35

7

5

5

5

1

$1 \frac{2}{5}$

$\begin{array}{rr}18 & 19 \\ 6 & 6 \\ 12 & 10 \\ 5 & 3 \\ 1 & 1 \\ 6 & 8 \\ 10 & 3 \\ 7 & 6 \\ 5 & 4\end{array}$

STEP C: Now that the bargaining situation has been set up in this form, the Bargain Solver can readily derive the optimum solution to the situation by means of the systematic trial-and-error method. It is worth noting that this is another situation in which the optimum solution is not intuitively obvious, even though it is a relatively simple collective bargaining situation. However, by means of the systematic trial-and-error method the optimum solution is easily calculated (Table 14).

A comparison of products indicates that a maximum point was reached in the second STEP 2 transaction, where Labor gives up MR-1, MR-2, MR-3, LO-2 and LO-5 in exchange for LR-1, LR-2, LR-3, LR-4, LR-7, MO-1 and MO-2. In this transaction Labor gains 18 and Management gains 16, for a product of 288 . This is the optimum solution to this bargaining situation. The values indicated are the most that each party should reasonably expect to gain from this particular situation. If an agreement had been made to abide by the solution derived by Bargain Solver, this is the solution that would be binding upon both parties.

\section{Games Bargaining Appraised}

Several features of the Games Bargaining just described require examination: the nature of the resulting bargain; the equality of bargaining gains and of strength of bargaining position implied by the system; the importance of frank: evaluation; and the advantages of the system over conventional arbitration. 


\begin{tabular}{|c|c|c|c|c|c|c|c|c|c|}
\hline \multirow[b]{3}{*}{$\begin{array}{l}\text { STEP } 1 \\
\text { Each party gives up } \\
\text { items he possesses } \\
\text { that the other } \\
\text { party values more. }\end{array}$} & \multicolumn{2}{|c|}{ Solutions } & \multicolumn{3}{|c|}{ LABOR } & \multicolumn{3}{|c|}{ MANAGEMENT } & \multirow[b]{2}{*}{$\begin{array}{l}\text { Prod- } \\
\text { UCT }\end{array}$} \\
\hline & $\begin{array}{l}\text { Labor } \\
\text { Gives }\end{array}$ & $\begin{array}{l}\text { Manage- } \\
\text { ment } \\
\text { Gives }\end{array}$ & Loss & Gain & Net & Loss & Gain & Net & \\
\hline & $\begin{array}{l}\text { MR-1.2.3 } \\
\& \\
\text { LO-2.5 }\end{array}$ & $\begin{array}{c}\text { LR-3.4.7 } \\
\& \\
\text { MO-1.2 }\end{array}$ & 45 & 39 & -6 & 26 & 67 & 41 & -246 \\
\hline $\begin{array}{l}\text { STEP } 2 \\
\text { Party with greater } \\
\text { gain gives up his } \\
\text { equally valued } \\
\text { items. }\end{array}$ & $\begin{array}{l}\text { MR-1.2.3 } \\
\stackrel{\&}{L}=2.5\end{array}$ & $\begin{array}{c}\text { LR-2.3.4. } \\
5.7 \\
\& \\
\mathrm{MO}-1.2\end{array}$ & 45 & 46 & 1. & 33 & 67 & 34 & 34 \\
\hline $\begin{array}{l}\text { STEP } 3 \\
\text { Party with greater } \\
\text { gain gives up one } \\
\text { at a time his items } \\
\text { which he values } \\
\text { more than the other } \\
\text { party does. } \\
\text { Compare products. }\end{array}$ & $\begin{array}{l}\text { MR-1.2.3 } \\
\stackrel{\&}{\& O-2.5}\end{array}$ & $\begin{array}{c}\text { LR-1.2.3. } \\
4.5 .7 \\
\& \\
\mathrm{MO}-1.2\end{array}$ & 45 & 64 & 19 & 52 & 67 & 15 & 285 \\
\hline $\begin{array}{l}\text { Now a different } \\
\text { party has the } \\
\text { greater gain and } \\
\text { STEPS } 2 \text { and } 3 \text { must } \\
\text { be repeated. }\end{array}$ & & & & & & & & & \\
\hline $\begin{array}{l}\text { Step } 2 \\
\text { Repeat }\end{array}$ & $\begin{array}{l}\text { MR-1.2.3 } \\
\& \cdot \\
\text { LO-2.5 }\end{array}$ & $\begin{array}{c}\text { LR-1.2.3. } \\
4.7 \\
\& \\
\mathrm{MO}-1.2\end{array}$ & 45 & 63 & 18 & 51 & 67 & 16 & 288 \\
\hline $\begin{array}{l}\text { STEP } 3 \\
\text { Repeat }\end{array}$ & $\begin{array}{l}\text { MRR-1.2.3 } \\
\& \\
\text { LO-2.4.5 }\end{array}$ & $\begin{array}{c}\text { LR-1.2.3. } \\
4.7 \\
\& \\
\mathrm{MO}-1.2\end{array}$ & 48 & 63 & 15 & 51 & 69 & 18 & 270 \\
\hline $\begin{array}{l}\text { STEP } 2 \\
\text { Repeat }\end{array}$ & $\begin{array}{l}\text { MR-1.2.3 } \\
\& \\
\text { LO-2.4.5 }\end{array}$ & $\begin{array}{c}\text { LR-1.2.3. } \\
4.5 .7 \\
\& \\
\mathrm{MO}-1.2\end{array}$ & 48 & 64 & 16 & 52 & 69 & 17 & 272 \\
\hline
\end{tabular}

\section{Table 14}

\section{The Better Bargain}

In the hypothetical negotiations in the vehicle industry, there might have been no trade at all, or at best a barely satisfactory one, if the scope of the bargain had not been enlarged. In the original bargaining situation, where LR-1, LR-2, MR-1 and MR-2 were the only items involved, it was seen that the proposal to exchange LR-1 and LR-2 for MR-1 and MR-2 resulted in a stalemate. ${ }^{31}$ If the optimum solution were derived from this original bargaining situation, it would be found to be MR-1 in exchange for LR-1 and LR-2. In this transaction Labor in terms of its own numerical valuations loses 23 and

31. See p. 682 supra. 
gains 24 for a net gain of 1, while Management loses 25 and gains 35 for a net gain of 10 . The product of the gains, $1 \times 10$, is 10 . Labor's gain of 1 is so small that it is not inconceivable that Labor would refuse to enter into the bargain at all, especially when Management would be getting a gain so large in comparison. In any event, the product of $1 \times 10$, or 10 , is still a far cry from $18 \times 16$, or 288, obtained from the broadened bargain. In the hypothetical example an agreement to settle the bargaining dispute by the Games Bargaining system resulted in significant gains to both parties; and this should generally be the result. In any event, no matter what the bargaining situation might be, agreeing to settle by Games Bargaining could not result in a loss from the parties' combined viewpoint.

It should also be noted, once more, that the solution obtained by the Games Bargaining system was, at least partially, an "integrative" one. It shifted the context of the bargain, and introduced new satisfactions in place of old and barren bones of contention.

\section{Equality of the Parties}

In two separate yet related ways Games Bargaining provides for equality of the contending parties : first, the tendency of the system is to make the gains of the parties equal; and second, the system not only assumes but enforces equality of bargaining power between the parties.

Equality of gain between the parties is clearly a desirable feature of any bargaining solution, at least from the combined viewpoint of the parties. This is especially true when the parties are equal in position before they enter the bargain-that is, when they have equal bargaining power. The Games Bargaining outlined here will not necessarily result in absolutely equal gains to each of the parties, and yet to the extent that it broadens the scope of the bargain it does tend to make the gains more equal, as was seen in the hypothetical example involving the vehicle industry. ${ }^{32}$ Furthermore, if it proved to be desirable, a flat guarantee of equal gains could probably be introduced into the system without great difficulty. ${ }^{33}$

32. See p. 684 supra.

33. A guarantee of equal gains would be achieved by the inclusion in the bargaining situation of an adjustable item such as a wage increase or decrease. How the inclusion of such an item would achieve this result requires a fairly elaborate explanation, which will only be sketched in here.

In the most complicated Bill-Jack situation, pp. 672-76 supra, the optimum solution was found to entail a gain for Bill of 12 units of satisfaction and for Jack of 5 units of satisfaction. Assuming that the parties were on the same valuation scale, this solution would not be the very best of all possible solutions within the limits of that bargaining situation. As was explained in note 8 supra, an even better solution involving the same aggregate gain of 17 for the parties would involve an $8 \mathrm{r} / 2$ and $8 \mathrm{y} / 2$ split. The product of payoffs for this split would be $721 / 4$, whereas the product of pay-offs for the 12 and 5 solution is only 60 . If Bill could somehow make a "side payment" of $31 / 2$ units of satisfaction to Jack-bringing Bill's net gain down to $8 \mathrm{x} / 2$ and Jack's up to $8 \mathrm{t} / 2$-then the even better optimum solution would be achieved. (Alternatively, the games theorist would achieve a better optimum solution by employing a "mixed strategy," see note 18 stpra, but Nash 
Inherent in the system, on the other hand, would be the assurance that each of the parties would enter the trade with equal bargaining power. That is to say, neither party would be able to demand and get a more favorable bargain for itself, at the expense of the other party, simply by virtue of being able to bring more economic pressure to bear. There is no way for such pressure to be exerted in the Games Bargaining system here proposed. ${ }^{34}$ This feature of Games Bargaining might well be a disadvantage in the eyes of some; a cogent answer, however, is that it is the national policy in labor disputes to accord to management and labor equality of bargaining power. ${ }^{35}$ Games Bargaining would give substantial, automatic effect to a policy that is now often difficult to apply.

If the use of economic leverage has no place in Games Bargaining, there still remains another of the ways in which the parties can, as in ordinary collective bargaining, influence the result. They would still be free to try to bluff. This point, which may prove to be as serious an obstacle as it is in traditional collective bargaining, requires separate examination.

has pointed out that it can also be achieved in a "pure strategy" solution if there are "sidepayments" involved. Nash, sitpra note 2, at 161.) Such side payments would have to be made in a common unit of value-the obvious example is money. Thus, for example, if Bill's and Jack's units of satisfaction represented dollars, the side payment necessary to equalize their gains from the bargain would be $\$ 3.50$.

In a collective bargaining situation, it is believed, putting into the bargain an adjustable item-such as wage increases and decreases at $\$ .03$ intervals-would provide a rough equivalent to side payments. Taking the labor-management hypothetical once more, let us assume that a wage increase or decrease of $\$ .03$ would be worth one unit of satisfaction to each of the parties; one of $\$ .06$, two units of satisfaction; and so forth. In order to make the parties' gains in the optimum solution equal, a side payment from Labor to Management of 1 unit of satisfaction would be necessary, bringing Labor's gain down to 17 and Management's up to 17 , for a product of pay-offs of 289 instead of the 288 initially obtained. Such a side payment would be made by Labor's giving Management a wage decrease of $\$ .03$ an hour. Since Labor already obtains a wage increase item of $\$ .12$ an hour, $\mathrm{LR}-3$, the net effect of the transaction would be a wage increase of $\$ .09$ an hour.

The introduction of adjustable items involves special problems of its own which are beyond the scope of this comment. Suffice it to mention that although adjustable items would introduce side payments, they would be side payments of a restricted nature. Such restricted side payments might change the systematic trial-and-error method outlined here, rendering STEP 3 unnecessary. It should also be noted that side payments apparently would require that the parties be on the same scale of valuation.

34. The author does not claim that the system could not possibly be loaded to favor one party at the expense of the other; he has not, however, discovered a way of so loading it.

35. In $\S 1$ of the National Labor Relations Act inequality of bargaining power is found to be a burden on the flow of commerce. It is declared to be the policy of the United States to eliminate the causes of obstructions to the free flow of commerce. Thus, the policy of the United States is the elimination of inequality of bargaining power; or, in other words, the achievement of equality of bargaining power. 49 STAT. 449 (1935), as amended, 29 U.S.C. \& 151 (1952).

An 1896 dissent by Holmes was one of the early landmarks in the development of the national policy of equality of bargaining power:

"One of the eternal conflicts out of which life is made up is that between the etfort of evcry man to get the most he can for his services, and that of society, dis- 


\section{The Importance of Frank Evaluation}

As has been seen, the optimum solution in Games Bargaining depends upon the valuations that the parties put upon the items in the trade. If those valuations are accurate, then the solution obtained in a given situation will be the best possible solution from the joint viewpoint of the parties. The reverse of the coin is that any other solution to the situation would be less desirable from the joint viewpoint of the parties. If the valuations put on the items are not accurate, then the solution will vary-and, necessarily, a less desirable bargain will result. If, then, the valuations are not accurate, the optimum solution obtained by Games Bargaining will not be the best of the possible bargains between the parties. It follows that accurate evaluation is necessary in order to obtain the best possible solution by means of the Games Bargaining system outlined here; and it follows that honest evaluation is necessary as well.

But in ordinary bargaining, the valuations that the parties pretend to put on the items are likely to be something less than candid. Each party may be tempted to depreciate the items the other party has, in the hope of securing those items at a lower price than he would really be willing to pay; and to magnify the value of the items he has himself, in the hope of being able to get a higher price for those items. What, then, if labor and management should approach Games Bargaining evaluation in this spirit? What would be the effect upon the optimum solution of their declaring numerical valuations that were distorted in the same way as are their less explicit valuations in ordinary bargaining?

A start in exploring the answer may be made by examining again the hypothetical example involving negotiations in the vehicle industry, and comparing the optimum solution obtained in that example with the solutions that would have been obtained if some of the items had been misevaluated. Three examples will give a hint of the effects to be anticipated from misevaluation.

guised under the name of capital, to get his services for the least possible return. Combination on the one side is patent and powerful. Combination on the other is the necessary and desirable counterpart, if the battle is to be on carried on a fair and equal way."

Vegelahn v. Guntner, 164 Mass. 92, 108, 44 N.E. 1077, 1081 (1896).

Millis and Brown offer an analysis and historical account of equality of bargaining power as an aim of public policy:

"In America, as in other countries, by a long slow process labor moved from the early master-servant relationship-for many even bond servitude or slaverytoward that equality of status and bargaining power between free employees and their employers, resulting in joint determination of the conditions under which people worked, that was envisioned by the Wagner Act. It was a process by which workers gained, although never universally, freedom to act in concert for their common benefit and power to act effectively. Governmental policy moved from one of suppression to more or less toleration and finally to acceptance and encouragement of labor organization and collective bargaining."

See Miluis \& Brown, From the Wagner Act to Taft-Hartley : A Study of National Labor Policy and Labor Relattons 4 \& passim (1950). 
First, assume that Labor underevaluates one of the items possessed by Management. $^{36}$ On item LR-3, Labor declares a valuation of 7 instead of the 12 that represents Labor's true appraisal of the item. If the optimum solution is calculated using this deflated valuation, the resulting bargain will be the trade of LR-1, LR-2, LR-4, LR-5, LR-7, MO-1 and MO-2 in exchange for MR-1, MR-2 and LO-5. Comparison of this solution with the solution obtained when LR-3 was properly evaluated shows that a less profitable bargain has resulted:

\begin{tabular}{ll}
$\begin{array}{l}\text { Labor Accurately } \\
\text { Evaluates LR-3 }\end{array}$ & $\begin{array}{l}\text { Labor Undereval- } \\
\text { uates LR-3 by } 5\end{array}$ \\
\hline
\end{tabular}

Labor's Gain (in terms of real valuation)

Management's Gain

Product of Gains
18

16

288
15

15

225

Not only is this distorted solution not as good from the joint viewpoint of the parties, it is not as good for Labor-here Labor would gain only 15 units of satisfaction, while if it had properly evaluated $L R-3$ it would have received 18 units of satisfaction.

Now let us assume that Labor overevaluates one of the items it possesses. Labor declares a valuation of 38 on MR-1, instead of the 23 it actually considers the item to be worth. If the optimum solution is calculated using this inflated valuation, the resulting bargain will be LR-3, LR-4, LR-5, LR-7 and MO-2 in exchange for MR-2, MR-3, LO-2 and LO-5. Once again a less profitable bargain has resulted, and once again Labor has lost by virtue of its misevaluation:

Labor's Gain (in terms of real valuation) Labor Accurately Evaluates MR-1

Labor Overeval-

\begin{tabular}{lccc} 
& $\begin{array}{c}\text { Labor Accurately } \\
\text { Evaluates MR-1 }\end{array}$ & & $\begin{array}{c}\text { Labor Overeval- } \\
\text { uates MR-1 by 15 }\end{array}$ \\
\cline { 2 - 2 } $\begin{array}{lcc}\text { Labor's Gain (in terms of real } \\
\text { valuation) }\end{array}$ & 18 & 11 \\
Management's Gain & 16 & 11 \\
Product of Gains & 288 & 121
\end{tabular}

It is apparent from these two examples that by following its natural inclination to exaggerate the worth of its own items and depreciate those of the other party, a party may not only spoil the joint bargain somewhat, but also reduce his own possible gains. If a party underevaluates an item, this may lead to his not receiving that item in the optimum solution worked out by the Bargain Solver, whereas an accurate evaluation would have secured him that item. If a party overevaluates an item, on the other hand, he may make it more likely that he will have to give up other items he really values more than the item he has misevaluated.

But this is only one side of the picture. By misevaluating somewhat differently, Labor might have actually profited from its waywardness. Thus if, instead of overevaluating its own item MR-1 by 15 , as in the immediately previous example, Labor had overevaluated it by 7, declaring it to be worth 30

36. The list of the items and their valuations is to be found on pp. 683-84 supra. 
units of satisfaction, the following bargain would result: LR-1, LR-2, LR-3, LR-4, LR-5, LR-7, MO-1 and MO-2 would be exchanged for MR-1, MR-2, MR-3, LO-2 and LO-5. The pay-offs would be as follows:

Labor's Gain (in terms of real

\section{Labor Accurately} Evaluates MR-1 valuation)

Management's Gain

Product of Gains
Labor Overevaluates MR- 1 by 7

Although this bargain is not as good from the joint viewpoint of the parties, since the product of gains has been reduced, it is actually a better one from Labor's provincial viewpoint, for Labor has added a unit of satisfaction to its net gain as a result of its misevaluation.

In sum, although misevaluation will impair the bargain from the joint viewpoint of the parties, it will not necessarily impair it from one party's provincial viewpoint. In certain circumstances misevaluation by the parties may in effect be punished, but in others it may be rewarded. The serious question arises whether the parties are likely to be so tempted to distort their valuations with the hope of selfish advantage as to impair the utility of Games Bargaining.

If a party could be confident that certain misevaluations would be sure to redound to its own advantage, it may be assumed that the temptation to finagle would be too great; there would be no hope of getting accurate evaluations. But the difficulty does not seem to be so dire. Although the parties might try to calculate beforehand just what sort of misevaluations would be most likely to be to their own advantage, such calculations would require accurate foreknowledge of the corresponding valuations to be made by the other party. ${ }^{37}$ And this information would not be disclosed in Games Bargaining at the evaluation stage. In other words, even if a party knew which kind of misevaluation was most likely to be advantageous, he could never be sure that he would gain rather than lose if he succumbed to the temptation to misevaluate. Thus, for a party to be sure of gaining from the distortion of his valuations, he would have to have a reliable crystal ball. Furthermore, there would be the threat of retaliation. If one party started to engage in manipulative tactics at the ex-

37. As regards underevaluation of the other party's items and overevaluation of its own items, a misevaluating party stands to gain only if the item would be "tradable" if honestly evaluated and remains tradable after being misevaluated. If the item were tradable before misevaluation but untradable afterward, then the misevaluating party would lose (if the item were untradable before, then such misevaluation would not affect either its tradability or the resulting gain of the party misevaluating). Tradability depends on the relation between the two parties' valuations; therefore, in order to predict the effect of his misevaluation, the misevaluating party must be able to predict the other party's valuation on the item in question.

There are, of course, two other sorts of misevaluation possible: underevaluation of one's own items, and overevaluation of the other's. Such misevaluation could not ever benefit the party committing it; either it would not affect his gains, or else it would diminish them. 
pense of the other, the suffering party could not be expected to stand idle; it too would start finagling. The result of systematic misevaluation by both parties would eventually be a narrowing of the bargain down to the point where neither party gained anything at all. The result of unsystematic misevaluation would be chaos.

It may be that some sort of check against misevaluation could be added to the Games Bargaining outlined here; but even without such a check, the system would work where there was a modicum of good faith between the parties. It would, of course, work best where there was complete honesty in the declaring of evaluations. Such honesty might be engendered by fear of retaliation or by mutual trust, by uncertainty about the chances of gain from bluffing or by an affirmative desire to achieve the best of possible joint solutions. The extent to which candid evaluation could be achieved would be a major factor in determining the success of Games Bargaining in practice; the extent to which candid evaluation can be achieved cannot be determined until Games Bargaining has been attempted in practice.

In contrast to calculated misevaluation for the purpose of besting the other party, there is also in ordinary bargaining the problem of emotion sneaking into evaluation; here, Games Bargaining should by its nature tend to induce calm reasonableness in the parties. To the extent that the parties are made to put specific valuations on the bargaining items, Games Bargaining should tend to avoid impasses where work is halted "on principle" because there is "no price" high enough for a particular item. It should tend to eliminate situations where a party declares that it must get item $X$, or else! It is when parties get to thinking in such absolute terms that negotiations break down, and strikes or lockouts result. The emphasis in Games Bargaining is towards encouraging the parties to think in relative terms, to avoid putting infinite price tags on specific items. To the extent that the parties do negotiate by means of Games Bargaining, some of the emotion that almost inevitably creeps into traditional collective bargaining will be avoided. The process of evaluating should, in this respect, reinforce the effect that broadening the bargain would havethe effect, that is, of making it easier for the parties to negotiate dispassionately.

\section{Arbitration's Advantages Without Its Drawback}

If the Games Bargaining were preceded by a submission agreement binding the parties to abide by its results, there could be a guarantee of no work stoppage. This, of course, is the major advantage of arbitration as well; but in Games Bargaining the big advantage of arbitration would be obtained without paying its big price. In arbitration the parties must surrender control of the decision-making process to an outside party, who may not be as aware of their needs as they themselves are. In seeking a middle ground that will not offend either party too greatly, an arbitrator may come to a solution that is unsatisfactory to both. In Games Bargaining the parties retain the essential power to influence the outcome of the bargain-the power to evaluate the items in the trade. All they give up to the outsider-the Bargain Solver-is 
the administrative power necessary to use the valuations in calculating an optimum solution. And yet the system can still have arbitration's big advantage: the guarantee of a binding peaceful solution. In a sense the parties can have their cake and eat it too.

\section{Summary and Conclusions}

Games Bargaining has been depicted as a blending of two notions. Following Lasswell and McDougal's concept of integrative solutions, the parties are made to define their collective bargaining situation as broadly as is practically possible. Then Nash's Theory of Games technique for deriving optimum solutions is applied to the situation so defined to discover what the resulting agreement should be. This technique was illustrated here in a series of boy-toy examples involving Bill and Jack, where four alternative methods of deriving optimum solutions were examined. The fourth method, designated the systematic trial-and-error method, was shown to furnish a calculational short-cut in dealing with more complex bargaining situations. Then a hypothetical collective bargaining dispute in the vehicle industry was posed, and Games Bargaining applied to it. The parties submitted the dispute to a Bargain Solver, agreeing to be bound by the results of his calculations. He called for expanded lists of trade itemsboth requests and offers- from both of the parties; got each of the parties to evaluate all the items; and calculated the optinum solution by means of the systematic trial-and-error method.

The Games Bargaining solution thus obtained could be arrived at swiftly and dispassionately ; and, more important, it was certain to be the best possible solution for both parties together. Furthermore, it was a broad, and at least partially "integrative," solution.

The parties gave up a certain manipulative power over the bargaining, since their evaluations once made could not be changed, but they did not abdicate power to one another, nor to a third person; the Bargain Solver exercised no arbitrary power of choice. The parties, in submitting their bargaining to the Bargain Solver, had to forego any further horse-trading, politicking or wielding of pressure; but they were assured of equal bargaining power by the very nature of the system, and were assured as well of an absolutely impartial maximization of their joint gains. The parties retained their influence over the most important element in the bargain-the most important element in any bargain - the evaluation of the items to be traded. But in the evaluation process the parties lost some of their freedom to bluff and outwit each other, for Games Bargaining involves dangers of loss to a party who misevaluates.

Evaluation may prove to be a two-fold stumbling block. It cannot be predicted with certainty that the built-in sanctions in Games Bargaining would be stringent enough to deter the parties from distorting the process by deliberate misevaluation. This, it must be said, remains to be seen. Again, even assuming the parties are candid, there is the question whether they can succeed in evaluating accurately. Games Bargaining absolutely requires that the parties give relative but concrete numerical valuations to the items in the trade, 
and in this field such numerical evaluation has not, to say the least, acquired the ease of long usage. But quantification of values is by no means an impossibility, either theoretical or empirical; and how real a difficulty it will be cannot be known until it has been tried.

There are difficulties to be worked out, but the system outlined seems promising enough to warrant the necessary effort. For instance, to speculate briefly: in areas where the national interest requires the settlement of labor disputes without work stoppage-the so-called national emergency situations - a compulsory settlement by Games Bargaining might well serve the interests of the nation. It would serve the interests of the parties as well: they would be assured of substantial gains from Games Bargaining compelled by statute. Further speculation is prompted by the fact that automation seems to be looming on the horizon in so many industries. With the advent of automation on an ever widening scale, it is likely that bargaining situations will revolve about the problem of apportioning the benefits of automation between labor and management, rather than continue as simple trades back and forth between them of factors already in existence. Such factors are likely to be merely the balancing items in the trade. This is exactly what happened in the hypothetical dispute in the vehicle industry described here: in the final analysis the result amounted to a division of the benefits resulting from the automation of $B$ and $D$ assembly lines.

The system of Games Bargaining presented here is not offered as a panacea for labor-management bargaining, nor even as a presently workable system. It is intended only as a first approximation, a pilot model from which a workable vehicle of a new way of collective bargaining might eventually be designed. The structure outlined could be varied in many details, some few of which have been indicated; it could, no doubt, be redesigned and streanlined; it could, above all, be given a trial whirl-for the most important information now missing is performance data. Some empirical testing in actual collective bargaining situations would seem to be the next logical step. If what has been presented should provoke some such experimentation, then the modest aims of this comment will be fulfilled.

Layman E. AlLEN $\dagger$

†Member, Class of 1956, Yale Law School. 